\title{
UCRL-CONF-206151
}

LAWRENCE LIVERMORE N A T IO N A L LABORATORY
Special Session of EuroPVM/MPI 2004: Current Trends in Numerical Simulation for Parallel Engineering Environments (ParSim 2004)

C. Trinitis, M. Schulz

August 20, 2004

11th European PVM/MPI Users' Group Meeting Budapest, Hungary September 19, 2004 through September 22, 2004 
This document was prepared as an account of work sponsored by an agency of the United States Government. Neither the United States Government nor the University of California nor any of their employees, makes any warranty, express or implied, or assumes any legal liability or responsibility for the accuracy, completeness, or usefulness of any information, apparatus, product, or process disclosed, or represents that its use would not infringe privately owned rights. Reference herein to any specific commercial product, process, or service by trade name, trademark, manufacturer, or otherwise, does not necessarily constitute or imply its endorsement, recommendation, or favoring by the United States Government or the University of California. The views and opinions of authors expressed herein do not necessarily state or reflect those of the United States Government or the University of California, and shall not be used for advertising or product endorsement purposes. 


\section{Special Session of EuroPVM/MPI 2004: \\ Current Trends in Numerical Simulation for Parallel Engineering Environments \\ ParSim 2004}

Simulating practical problems in engineering disciplines has become a key field for the use of parallel programming environments. Despite remarkable progress in both CPU power and network technology as well as extensive developments in numerical simulation and software integration, this field still provides and will continue to provide - challenging problems for both computer scientists and engineers in the application disciplines. In addition, the appearance of new paradigms like Computational Grids or E-Services has introduced new opportunities and challenges for parallel computation. This rich and complex environment demands for an intensive cooperation between scientists from both the engineering disciplines and computer science.

Since its introduction at EuroPVM/MPI 2002, ParSim is dedicated to providing a forum for interdiscplinary cooperations in this important field. It brings together researches with different backgrounds to discuss current trends in parallel simulation. It is our hope that this offers the opportunity to establish new contacts, to open up new perspectives, and to foster cooperations across disciplines. The EuroPVM/MPI conference series, as one of Europe's prime events in parallel computation, serves as an ideal surrounding for ParSim. This combination enables the participants to present and discuss their work within the scope of both the session and the host conference.

This year, 10 papers were submitted to ParSim and we selected five of them. They cover both computer science aspects, including cache optimization, as well as experience with special applications from various fields of engineering and physics. We are confident that this resulted in an attractive program and we hope that this session will be an informal setting for lively discussions.

Several people contributed to this event. Thanks go to Jack Dongarra, the EuroPVM/MPI general chair, and to Peter Kacsuk and Dieter Kranzlmüller, the PC chairs, for their encouragement and support to continue the ParSim series at EuroPVM/MPI 2004. We would also like to thank the numerous reviewers, who provided us with their reviews in such a short amunt of time and thereby helped us to maintain the tight schedule. Last, but certainly not least, we would like to thank all those who took the time to submit papers and hence made this event possible in the first place. 
We hope this session will fulfill its purpose to provide new insights from both the engineering and the computer science side and encourages interdisciplinary exchange of ideas and cooperations. We hope that this will continue ParSims tradition at EuroPVM/MPI.

\section{Carsten Trinitis}

Lehrstuhl für Rechnertechnik und Rechnerorganisation (LRR)

Institut für Informatik

Technische Universität München, Germany

Carsten.Trinitis@in.tum.de

Martin Schulz

Center for Applied Scientific Computing

Lawrence Livermore National Laboratory

Livermore, CA

schulz5@llnl.gov 